\title{
Precursors Of Emotional Stability, Stress, And Work-Family Conflict Among Female Bank Employees
}

Clifford Kendrick Hlatywayo, University of Fort Hare, South Africa Tawanda Zingwe, University of Fort Hare, South Africa Tatenda Shaleen Mhlanga, University of Fort Hare, South Africa Bukhosi Dumoluhle Mpofu, Lupane State University, Zimbabwe

\begin{abstract}
Women exposure to quality education and equity legislation has accelerated their participation in the workplace. The study investigated the relationship between emotional stability, stress, and work-family conflict among female bank employees in the border region of the Eastern Cape, South Africa. Findings highlighted significant positive relationships between work-family conflict, stress, and neuroticism. The findings support most relationships found in literature. Correlations were also found amongst biographical data of female banking employees. The implications of this study are discussed along with recommendations for future research and professional managerial practice.
\end{abstract}

Keywords: Work-Family Conflict; Stress; Emotional Stability; Neuroticism; Banks; Females

\section{INTRODUCTION}

lobally, there has been an escalation in the number of women joining the workforce (Noor, 2006) whether single, married, or women with children (Kroska, 2004). In South Africa, equity legislation, such as the Employment Equity Act of 1998, has been a catalyst as employers are required to consider previously disadvantaged groups under the apartheid regime. The Labour Market Review Report (2006) highlights such government policies and programmes as fair as they allow equal access to the labour market for women. The South African banking sector has a dominantly female labour force. These employees experience different types of workfamily conflict because of the long working hours, work overload, inflexibility in work operation, and the strict banking policies regarding vacations and office timing (Maqsood, Muhammad, \& Sallem, 2012). Women face a series of challenges as they are expected to balance family responsibilities and work responsibilities.

Most work-family conflict issues have been well documented by western researchers while far less has been done in Africa and with special reference to South Africa's female banking employees (Burger \& Woodlard, 2005). The study attempted to explore the sources of work-family conflict of female bank employees in South Africa, assess the impact of role conflict on work and on the well-being for working women, identify the variables that interfere with their work-family balance, and suggest ways and means for striking a balance between domestic and professional duties.

In order to help women manage the demands of both work and family, it is necessary to explore the origin s and correlations of work-family conflict and work stressors, and to try to find a support system at the level of the family and workplace for resolving it.

The main objective of the study was to:

- Investigate the relationship between work-family conflict, stress, and emotional stability among Standard Bank female employees. Identify the variables that interfere with work-family balance among female bank employees. 


\section{HYPOTHESES}

$\mathbf{H}_{\mathbf{1}}$ : There is a significant positive relationship between stress and work-family conflict.

$\mathbf{H}_{2}$ : There is a significant negative relationship between emotional stability and work-family conflict.

$\mathbf{H}_{3}$ : There is a significant negative relationship between emotional stability and stress.

$\mathbf{H}_{4}$ : There is a significant positive relationship between family stress and work-family conflict

$\mathbf{H}_{5}$ : There is a significant positive relationship between work stress and work-family conflict.

\section{METHODOLOGY}

To test the hypotheses, a quantitative approach was adopted, using a survey questionnaire. Raosoft sample size calculator was used to calculate the recommended sample size. Ninety questionnaires were distributed and 72 usable questionnaires were returned giving a response rate of $80 \%$.

The reliability of appropriate sections of the questionnaire was tested using the Cronbach's Alpha.

Work-family conflict was measured using the Carlson, Kackmar, and Williams (2000) work-family conflict scale with a reported internal consistency reliability of 0.91 for the scale. The alpha value for work-family conflict in the study is 0.94 .

Work stress was measured using the modified version of the State Anxiety Inventory (SAI) by Spielberger, Gorsuch, and Lushene (1969). The alpha value for Work stress in the study is 0.71.

Family stress was assessed using a modified version of the Reeder Stress Inventory (RSI) by Reeder, Chapman, and Coulson (1968). The coefficient alpha for the 4-item measure reported is 0.75 . In the present study a reliability coefficient is 0.67 .

Emotional stability was measured using a neuroticism scale developed by Eysenck, Eysenck, and Barrett (1985). The scale has a reliability coefficient of 0.78 . In the coefficient alpha established for the measurement of neuroticism is 0.82 .

The data were analysed using the Statistical Package for the Social Sciences (SPSS Window version 12.0). Frequency analysis for the respondent's demographic and occupational variables was carried out. Subsequently, Pearson Correlation Analysis was used to examine the relationship between the study variables.

\section{RESULTS}

\section{Biographical Data vs. Variables}

Table 1 shows correlations between demographics and study variables. Age of the respondents shows a positive correlation with neuroticism $(\mathrm{r}=0.55630 ; \mathrm{p}=<.0001)$, family stress $(\mathrm{r}=0.54581 ; \mathrm{p}=<.0001)$, work stress $(\mathrm{r}=0.55459 ; \mathrm{p}=<.0001)$, strain-based conflict $(\mathrm{r}=0.57035 ; \mathrm{p}=<.0001)$, time-based conflict $\mathrm{r}=0.62110 ; \mathrm{p}=$ $<.0001)$, and behaviour-based conflict $(r=0.141424 ; p=0.0003)$. Experience shows a positive correlation with all of the study's variables but showed no significant correlation with behaviour-based conflict $(\mathrm{r}=0.17349 ; \mathrm{p}=$ 0.1450). Marital status had a positive correlation with all the variables except for behaviour-based conflict which did not indicate a significant correlation $(r=0.21864 ; \mathrm{p}=0.0650)$.

The number of children of the respondents shows a significant positive correlation with neuroticism $(\mathrm{r}=$ $0.65341 ; \mathrm{p}=<.0001)$, family stress $(\mathrm{r}=0.66670 ; \mathrm{p}=<.0001)$, work stress $(\mathrm{r}=0.65731 ; \mathrm{p}=<.0001)$, strain-based conflict $(r=0.66438 ; p=<.0001)$, time-based conflict $(r=0.66691 ; p=<.0001)$ and behaviour-based conflict $(r=$ $0.47961 ; \mathrm{p}=<.0001)$. Number of family members and working hours show a positive correlation with all the study variables. Work status of the employees showed no significant correlation with any of the variables. There was a significant negative correlation between occupation level and neuroticism $(\mathrm{r}=-0.50656 ; \mathrm{p}=<.0001)$, family stress $(\mathrm{r}=-0.46027 ; \mathrm{p}=<.0001)$, work stress $(\mathrm{r}=-0.53284 ; \mathrm{p}=<.0001)$, strain-based conflict $(\mathrm{r}=-0.51301 ; \mathrm{p}=<.0001)$, 
time-based conflict $(r=-0.57965 ; \mathrm{p}=<.0001)$ and behaviour-based conflict $(\mathrm{r}=-0.40485 ; \mathrm{p}=<.0001)$. Family responsibility, number of residing members and sole supporters of households showed a negative correlation with all the study variables shown in Table 1.

Table 1: Correlation among Stress, Work-Family Conflict, and Emotional Stability

\begin{tabular}{|l|c|c|c|c|c|}
\hline \multicolumn{1}{|c|}{ Variable } & Neuroticism & Family Stress & Work Stress & SBC & TBC \\
\hline \multirow{2}{*}{ Age } & 0.55630 & 0.54581 & 0.55459 & 0.57035 & 0.62110 \\
& $<.0001^{*}$ & $<.0001^{*}$ & $<.0001^{*}$ & $<.0001^{*}$ & $<.0001^{*}$ \\
\hline \multirow{2}{*}{ Experience } & 0.44315 & 0.46751 & 0.52210 & 0.46072 & 0.46750 \\
& $<.0001^{*}$ & $<.0001^{*}$ & $<.0001^{*}$ & $<.0001^{*}$ & $<.0001^{*}$ \\
\hline \multirow{2}{*}{ Marital Status } & 0.38373 & 0.37294 & 0.48118 & 0.36620 & 0.41081 \\
& $0.0009^{*}$ & $0.0013^{*}$ & $<.0001^{*}$ & $0.0016^{*}$ & $0.0003^{*}$ \\
\hline \multirow{2}{*}{ Number of Children } & 0.65341 & 0.66670 & 0.65731 & 0.66438 & 0.66691 \\
& $<.0001^{*}$ & $<.0001^{*}$ & $<.0001^{*}$ & $<.0001^{*}$ & $<.0001^{*}$ \\
\hline \multirow{2}{*}{ Work Status } & -0.17297 & -0.17318 & -0.21670 & -0.17287 & -0.16625 \\
& 0.1462 & 0.1457 & 0.0675 & 0.1465 & 0.1628 \\
\hline \multirow{2}{*}{ Occupation Level } & -0.50656 & -0.46027 & -0.53284 & -0.51301 & -0.57965 \\
& $<.0001^{*}$ & $<.0001^{*}$ & $<.0001^{*}$ & $<.0001^{*}$ & $<.0001^{*}$ \\
\hline \multirow{2}{*}{ Family Responsibility } & -0.73918 & -0.73423 & -0.68951 & -0.72138 & -0.66716 \\
& $<.0001^{*}$ & $<.0001^{*}$ & $<.0001^{*}$ & $<.0001^{*}$ & $<.0001^{*}$ \\
\hline \multirow{2}{*}{ Residing Members } & -0.45554 & -0.41428 & -0.46594 & -0.46593 & -0.48586 \\
& $<.0001^{*}$ & $0.0003^{*}$ & $<.0001^{*}$ & $<.0001 *$ & $<.0001^{*}$ \\
\hline \multirow{2}{*}{ Family Members } & 0.46556 & 0.41485 & 0.47108 & 0.49592 & 0.48632 \\
& $<.0001^{*}$ & $0.0003^{*}$ & $<.0001^{*}$ & $<.0001 *$ & $<.0001$ \\
\hline \multirow{2}{*}{ Working Hours } & 0.47468 & 0.43529 & 0.51284 & 0.47623 & 0.51327 \\
& $<.0001^{*}$ & $0.0001^{*}$ & $<.0001^{*}$ & $<.0001^{*}$ & $<.0001^{*}$ \\
\hline \multirow{2}{*}{ Sole Supporters } & -0.65926 & -0.65533 & -0.64510 & -0.66748 & -0.64718 \\
& $<.0001^{*}$ & $<.0001^{*}$ & $<.0001^{*}$ & $<.0001$ & $<.0001^{*}$ \\
\hline * $<0.01$ & & & &
\end{tabular}

\section{Hypotheses Testing}

$\mathrm{H}_{1}$ : There is no significant positive relationship between stress and work-family conflict. The results show that there is a significant positive correlation between stress and work-family conflict $(r=0.87068 ; \mathrm{p}=<.0001)$. When work-family conflict increases, stress increases. Therefore the null hypothesis was rejected.

$\mathrm{H}_{2}$ : There is a significant negative relationship between emotional stability and work-family conflict. There is a significant positive relationship between neuroticism and work-family conflict $(r=0.93077 ; p=<.0001)$ which suggests a direct negative relationship between work-family conflict and emotional stability since emotional stability is the opposite of neuroticism. Highly emotional people are low on neuroticism and will have low work-family conflict levels, therefore implying a negative association between emotional stability and work-family conflict. Therefore, the null hypothesis was rejected in favour of the alternative hypothesis.

$\mathrm{H}_{3}$ : There is a significant negative relationship between neuroticism and stress. The results shows there is significant positive correlation between neuroticism and stress $(r=0.92784 ; \mathrm{p}=<.0001)$ which suggests a direct negative relationship between stress and emotional stability since emotional stability is the opposite of neuroticism. Individuals who are emotionally stable have low neuroticism and will have low stress levels, therefore implying a negative association between emotional stability and stress. Therefore, this study rejects the null hypothesis.

$\mathrm{H}_{4}$ : There is no significant positive relationship between family stress and work-family conflict. There is a positive significant correlation between family stress and work-family conflict $(r=0.87026 ; \mathrm{p}=<.0001)$. The null hypothesis is rejected and the alternative hypothesis is accepted.

$\mathrm{H}_{5}$ : There is no significant positive relationship between work stress and work-family conflict. There is a positive significant correlation between work stress and work-family conflict $(\mathrm{r}=0.82201 ; \mathrm{p}=<.0001)$. The null hypothesis is rejected and the alternative hypothesis is accepted. 


\section{DISCUSSION}

As employees' working hours increase, so does the work-family conflict experienced by female bank employees. This is consistent with the findings of Frone, Yardley, and Markel (1997), Byron (2005), Wharton and Blair-Loy (2006), and Allan, Loudoun, and Peetz (2007). Most respondents work for eight to eleven hours a day while more than nine hours a day are regarded as long working hours. Managers and team leaders in banks feel a strong two-way pull in maintaining a balance between work and family due to long working hours. Their superior positions come with more responsibilities demanding extended working hours and leading to greater work-family conflict. From the study, it can be concluded that working hours is a major variable that affects the work-family balance. Time is a scarce resource; an increase in the time an employee is supposed to be at work will decrease the amount of time available at her disposal for family responsibilities and will result in increased conflict and stress on female bank employees.

One's work-family conflict increases as one's obligation to the family expands with the arrival of children. The more children individuals have, the greater their inability to harmonise family responsibilities with work demands (Grandey \& Cropanzano, 1999). It is argued that female employees who have younger children will find it more difficult to balance work and family responsibilities since such children require more attention from mothers. The more children to take care of, the more time - which is a scarce resource - will be required. Most respondents in the study have children, which requires their attention, while, at the same time, they work long hours, causing conflict and stress for female bank employees.

The number of dependants (live-in) an employee cares for was also a stressor, as correlation showed. Only 16 respondents in the study did not live with any family members, whereas 56 respondents lived with one or more members. More family responsibilities results in increased role expectations from the family domain thus causing conflict with the work role. The bigger the family, the more complex it becomes to manage the demands of both work and family. It is necessary to explore where such conflicts originate and the correlations of work-family conflict and work stressors so as to find support systems at the family level and in the workplace.

When work-family conflict of bank employees increases, so does the stress experienced by such employees. The finding supports that work-family conflict is significantly and positively correlated with stress. Such findings are consistent with research (Edwards \& Rothbard, 2005; Killien, 2000) that found that work-family conflict is strongly associated with stress. Increased pressures cause tension for the individual employee, resulting in stress. Such a positive association implies a direct relationship between work-family conflict and stress, where stress results in work-family conflict for female bank employees. According to Allen, Herst, Bruck, \& Sutton's (2000) findings, there is a positive relationship between work-family conflict and job-stress. Given these findings, we can say that work-family conflict does predict job stress. This means that the pressures that might stem from failing to balance work and family responsibilities may result in work stress affecting one's ability to effectively perform his work.

High neuroticism levels of female bank employees indicate that they are emotionally unstable and unable to cope with balancing work and family responsibilities; hence, there is a significant positive relationship between work-family conflict and neuroticism for these employees. This is consistent with the findings of Witt and Carlson (2006) which implies that individuals who are high on neuroticism experience more work-family conflict than individuals low on neuroticism. Individuals who report high neuroticism are less likely to deal well with increasing pressures in the work and family domains and therefore will be more likely to report high levels of work-family conflict than individuals who are low on neuroticism. The most stable bank employees are, the lower the stress they experience.

From the study, it can be noted that time-based work interference with family contributes more to timebased conflict than time based family interference with work. Time-based work interference with work had a mean score of 3.67, whereas time-based family interference with work has a mean score of 1.57 . This also holds for strainbased conflict where strain-based work interference with family has a mean score of 3.62 and strain-based family interference with work has a mean score of 3.37. The mean score for behaviour-based work interference with family is 2.10 , while for behaviour-based family interference with work, it is 1.97 . These findings show that female bank 
employees experience more work-family conflict than family-work conflict since the mean scores for work interference with family in all the forms of conflict are more than the mean scores for family interference with work. Female bank employees place the demands of work as being greater than the demands of family responsibilities. Time-based work interference with the work of all the mean scores contributes more to conflict since it has a mean score of 3.67. Clearly, working hours in banks and time schedules are the major contributors to conflict and stress experienced by female bank employees.

\section{RECOMMENDATIONS AND MANAGERIAL IMPLICATIONS}

Efforts to prevent work-family conflict and its consequences must come from the combined efforts of the employee and the employer. This can be achieved through collective efforts of control in the work and home environment. Employers try to organise the work environment so as to reduce work-family conflict and work-related consequences, while the employee and her family can take steps to address work-family conflict and the non-work and stress-related consequences. Employees must take steps to control demographic and personality variables that lead to work-family conflict while employers must take steps to control occupational variables that tend to cause work-family conflict and stress.

The study working hours of female bank employees seem to be a major contributor to the increased amount of work-family conflict and stress experienced. Bank management must implement supportive policies, such as the introduction of flexible banking working hours and supportive vacation policies. Controlling working hours, since long hours are a major antecedent of work-family conflict, will lead to reduced work-family conflict and, in turn, reduce stress among female banking employees. Empowering employees to control their work schedules is another technique that can be used to reduce the work-family conflict experienced by employees so as to reduce stress levels. By empowering female employees to have control over their working time ensures that they will be able to schedule their own work time in a manner that will enable them to better meet the demands of work and home and experience reduced work-family conflict and stress.

Introduction of personality tests in the selection process may also help banking institutions to control workfamily conflict and stress. Employing highly stable staff in the banking industry has an influence on work-family conflict and stress levels experienced by female bank employees. This will ensure that they select highly emotionally stable people who are able to control negative impulses and work-family conflict, which will result in lower work-family conflict and stress levels.

\section{AUTHOR INFORMATION}

Clifford Kendrick Hlatywayo earned a master in Industrial Psychology from the University of Fort Hare. The author is currently a PhD candidate with the University of Fort Hare. The authors' research interests are health and safety, competency development, training and development, and workplace dynamics. E-mail: vakendie@gmail.com (Corresponding author)

Tawanda Zingwe, is pursuing his PhD studies with the University of Fort Hare. He earned a Masters in Industrial Psychology from the University of Fort Hare in May 2013. His research interest is in organisational citizen behavior and conflict management. E-mail: tawazzingwe@gmail.com

Tatenda Shaleen Mhlanga earned her Bachelor of Administration in Human Resource Management in 2009, her Honors Degree in Industrial Psychology in 2010 and a Master's degree in Industrial Psychology in 2012 from University of Fort Hare. She is currently pursuing her PHD in Industrial Psychology. Tatendas' research area of interest is personality development. She is currently co-lecturing and co-supervising at Fort Hare University Industrial Psychology department. She is also the secretary of the student board of South African Board for People Practices. E-mail: atenda.mhlanga@gmail.com

Bukhosi Dumoluhle Mpofu is a Lecturer at Lupane State University and a holder of a master's degree in Commerce from Rhodes University that was attained in 2011. Research interests include: industrial psychology, online marketing, experiential marketing, and labor relations. E-mail: bhukhosimpofu@gmail.com 


\section{REFERENCES}

1. Allan, C., Loudoun, R., \& Peetz, D. (2007). Influences on work/non-work conflict. Journal of Sociology, 43, 219-39.

2. Allen, T. D., Herst, D. E., Bruck, C. S., \& Sutton, M. (2000). Consequences associated with work-to-family conflict: A review and agenda for future research. Journal of Occupational Health Psychology, 5, 278-308.

3. Burger, R., \& Woodlard, I. (2005). The state of the labour market in South Africa after the first decade of democracy. (CSSR Working Paper no. 133). Centre for Social Science Research.

4. Byron, K. (2005). A meta-analytic review of work--family conflict and its antecedents. Journal of Vocational Behaviour, 67, 169-198.

5. $\quad$ Carlson, D. S., Kackmar, K. M., \& Williams, L. J. (2000). Construction and validation of a multidimensional measure of work-family conflict. Journal of Vocational Behaviour, 56, 249-276.

6. Department: Labour, Republic of South Africa (2006) Women in the South African labour market 19952005. Retrieved from http://www.labour.gov.za/indexjsp

7. Edwards, J. R., \& Rothbard, N. P. (2005). Work and family stress and wellbeing: An integrative model of person-environment fit within and between the work and family domains. In Work and life integration: Organizational, individual and cultural perspectives (pp. 211-242). New York: Routledge.

8. $\quad$ Employment Equity Act. Act No. 55 of 1998.

9. Eysenck, S. B. G., Eysenck, H. J., \& Barrett, P. (1985). A revised version of the psychoticism scale. Journal of Personality and Individual Differences, 6, 21-29.

10. Frone, M. R., Yardley, J. K., \& Markel, K. S. (1997). Developing and testing an integrative model of the work-family interface. Journal of Vocational Behavior, 50, 145-167.

11. Grandey, A. A., \& Cropanzano, R. (1999). The conservation of resources model applied to work-family conflict and strain. Journal of Vocational Behavior, 54, 350-370.

12. Killien, M. G. (2004). Nurses' health: Work and family influences. Journal of Nursing Clinics of North America, 39, 120-132.

13. Kroska, A. (2004). Division of domestic work: Revising and expanding the theoretical explanations. Journal of Public Health, 11, 413-419.

14. Maqsood, A., Muhammad, M., \& Sallem, P. (2012). The impact of work-family conflict and pay on employee job satisfaction with the moderating affect of perceived supervisor support in Pakistan banking sector. Global Journal of Management and Business Research, 12, 45-54.

15. Noor, N. M. (2006). Locus of control, supportive workplace policies and work-family conflict. Journal of Psychology, 49, 48-60.

16. Reeder, L. G., Chapman, J. M., \& Coulson, B. (1968). Socio environmental stress, tranquilizers and cardiovascular disease. Proc Excerp Medica Intl Congress Series, 182, 226-238.

17. Speilberger, C. D., Gorsuch, R., \& Lushen R. (1969). State-trait anxiety inventory, preliminary test manual. Counselling Psychologists Press.

18. Wharton, A., \& Blair-Loy, M. (2006). Long work hours and family life: A cross-national study of employees' concerns. Journal of Family Issues, 27, 415-436.

19. Witt, L. A., \& Carlson, D. (2006). The work-family interface and job performance: Moderating effects of conscientiousness and perceived organizational support. Journal of Occupational Health Psychology, 11, 343-357. 